Studia UBB 政igitalia, Volume 63 (LXIII) 2018, June, Issue 1, 41-54

Published Online: 2018-06-30

DOI:10.24193/subbdigitalia.2018.1.03

\title{
Digital Humanities and e-commerce: considerations on digital monographs
}

\author{
Alessandra Di Tella \\ Alma Mater Studiorum, Università di Bologna
}

\begin{abstract}
Humanities", "Commerce" and "Monographs" are three terms that have been existed for a very long time. Nowadays, they are often conceptualized in a digital way that implies a radical paradigm shift in their main features. The aim of this article is to investigate the possibility of interaction between digital humanities and e-commerce, through their application to the genre of digital monographs. By "digital monograph" we mean born-digital, long-form, media-rich, scholarly publication, that rejects the print-based form (and so the e-book format) and takes advantage of the methods and tools of digital humanities. In particular, digital monographs re-think the traditional textuality of essays; textuality becomes "liquid" and multimodal. Because of publishing, obsolescence, discoverability, use, evaluation, etc. these products must be hosted on a publishing platform that is suitable for the scholarly needs both of the authors and of the final users. The link with e-commerce arises from the need of the publishers to sell the products of research, especially in countries where the academic publishing system is not based on University Presses but on commercial ones. This study wants to reflect on how the economic logic of profit and cultural logic can coexist in a digital publishing platform: is it possible to overcome the "monograph crisis"? What are the major problems that arise when selling an academic monograph? What business models could be the most suitable for this kind of publication? In what way can a publisher improve customer loyalty? The thesis of this article is that digital enhancement of the monograph plays a key role in its sale. The opportunities offered by the digital humanities, in fact, are not only a matter of format; they are, indeed, what makes the substantial difference in the quality of scientific communication. They enable the authors and the publishers to offer the consumer something that neither the print version, nor the e-book can do. First of all, a digital monograph allows a direct link with primary and secondary sources; secondly, it supports different layers of use and wider accessibility.
\end{abstract}


Moreover, it gives both the author and the reader, the possibility to better represent and understand the complexity of the research and of the methods and tools that are used. On the other hand, this article considers the infrastructure for producing and hosting these products and its importance in the development of a cultural community based on scholarly value creation. These are some of the issues that a digital publishing project needs to consider in order to sell its products and become sustainable. After discussing these questions, this article postulates a possible functioning business model of subscription based on the concept of cultural engagement. The conclusions concern the requirement of an editorial workflow that links together all the phases of production, from the author's composition to the reader's purchase.

Keywords: digital monographs re-think; e-commerce; digital tools; digitaltextuality layer

\section{Monographs: between the old and the new}

Writing about Digital Culture, Charlie Gere evokes a change of paradigm, to be seen both technically and philosophically, that concerns many aspects of human life: «Digitality can be thought of as a marker of culture because it encompasses both the artefacts and the systems of signification and communication that most clearly demarcate our contemporary way of life from others» (Gere, 12). Thinking the digital as the common denominator in theory and practice, this article wants to examine the possible interaction between digital humanities $(\mathrm{DH})$ and e-commerce, through their application in the field of digital monograph publishing. The key issue is represented by the digital, in the way it creates links and implications between these areas, both technically and philosophically speaking.

In recent decades, thanks to, and concurrently with the digital technical developments, scholarly practices and communication in the humanities have been changing radically in all their features: from methodologies and tools for research, to matters of production, dissemination and final fruition.

Starting from this change of paradigm, it's useful to study the best way for publishers to deliver and sell academic editorial products: is it possible to overcome the "monograph crisis"1? What are the major problems that arise when selling an

\footnotetext{
${ }^{1}$ For data, evidences and deepening about monograph crisis in a global perspective see Darnton, Robert. "The New Age of the Book", New York Review of Books, vol. 46, no. 5, 1999; Fitzpatrick, Kathleen. Planned
} 
academic monograph? What business models could be the most suitable for this kind of publications? In what ways can a publisher improve customer loyalty? To answer these core issues, we need to take a step back to introduce the exact context in which we are dealing.

Since the beginning of humanistic scholarly communication, the academic monograph has been the highest level of knowledge production and transmission. Still today, despite the press of journal articles, the monograph is considered the most suitable and validating format of academic writing, and the most considerable criterion in the evaluation of an academy's reputation and assessment of merit and achievement.

By "academic monograph" we mean a long-form scholarly work concerning a specific topic in detail, that provides research findings on that topic. «A monograph is what it means to work out an argument in full, to marshal all the relevant evidence, to provide a complete account of consequences and implications, as well as counterarguments and criticisms» (Willinsky).

The problem, in recent decades, has been the «monograph crisis» - or «chronic illness» (Thatcher), as some scholars prefer - first detected by Darnton in 1999. Started in the ' 70 s and becoming more and more pronounced during the ' 80 s and the '90s, the crisis affected monograph publishers, causing smaller print runs, a predilection for more commercial and marketable titles, an increase in the number of output/titles, and created a struggle for specialized research to find publishing outlets.

Among the causes of the crisis are an escalation in the price of periodicals (which forced the libraries to cut their purchase of monographs), cuts in academic budgets, and the economic downturn affecting the publishing industry in a broader sense.

Nevertheless, it seems reasonable that the causes of this crisis are not only strictly connected to the economy and trade; some are a matter of substance and concern the stasis of the genre, the deficiencies in development and effectiveness, the selfcentredness of academia and, last but not least, the obsolescence of the form caused by the new potential of the digital environment.

In fact, the digital turn has really up-ended the game, introducing new challenges for scholars, publishers, readers and for all attendees of the knowledge chain. The most widespread solution, today, is to complement the traditional book format with the e-book

Obsolescence: Publishing, Technology, and the Future of the Academy, New York, NYU Press, 2011; Greco, Albert N., Rodríguez, Clara E., and Wharton, Robert M. Culture and Commerce of Publishing in the Twenty-First Century, Palo Alto, Stanford University Press, 2006; Thatcher, Stanford G. "Thinking Systematically About the Crisis in Scholarly Communication" The Specialized Scholarly Monograph in Crisis: Or How Can I Get Tenure If You Won't Publish My Book?, Case, Mary (edited by), Washington DC, Association of Research Libraries, 1999; and above all Adema, Jannedee. "The monograph crisis revisited", Open reflections, 2015, https://openreflections.wordpress.com/2015/01/29/the-monograph-crisis-revisited/. 
monograph: a sort of transposition of the print-based version, from the analogical to the digital support. Although this publishing strategy is quite widespread today, and it does represent a significant entry in sales reports, it does not seem to have provoked the expected improvement, either for economic sustainability nor for the quality of research production and dissemination:

In their haste to migrate content from the print into the digital realm, publishers have typically not strayed far from traditional print format. When comparing an eBook with a print book, or a PDF to a print article, one is struck by how similar they look. Not only does this approach make for a suboptimal User Experience by not taking into account the limitations of the medium, it also fails to take advantage of the possibilities to make digital content more attractive to and relevant for users. (Campbell 2012, 271)

However, thanks to some visionary scholars' and publishers' efforts something different is being done: a new-born genre, the digital monograph, is trying to assert and develop itself. By digital monograph we mean a long-form research output genre with specific features that enhance the signification of the traditional print-based textual essay. First of all, they are born-digital, projected and composed for, and in, the digital environment, following the principles of digital rhetoric (Douglas). They gain from digital humanities tools and methods, being interactive, media-rich and based on a fluid and multimodal textuality. The result is that both the contents and the form (which are indissolubly linked) contribute to meaning-making to the same degree. ${ }^{2}$ The user/consumer/reader perspective also changes, because the use of a digital monograph totally differs from the traditional one: from accessibility and purchase methods, to their particular use of the format, to the contents' reshaping and visualization.

One good example of a full use of this new form is the case of Enchanting the desert, a monographic work by Nicholas Bauch (assistant professor of Geo-Humanities at Oklahoma University), published by Stanford University Press in the Digital Projects section. ${ }^{3}$ This is a born-digital examination of the photographer Henry Peabody's early-twentieth-century slideshow of the Grand Canyon, placed within the spatial framework of the Canyon itself, and embellished with rich overlays created through GIS mapping and virtual recreations of the topography. The accomplishment is a digital prototype for studying historical and cultural geography in which, as the author

\footnotetext{
${ }^{2}$ For an in-depth explanation of digital monographs see Riva, Massimo. "An Emerging Scholarly Form: the Digital Monograph”, Digitcult, vol. 2, no. 3, 2017, pp. 63-74, http://dx.doi.org/10.4399/97888255099087.

${ }^{3}$ This pioneering work has been financed by Mellon Foundation, that for years has been promoting innovation in scholarly communication. For further details about the monographs' project see https://mellon.org/ resources/shared-experiences-blog/monograph-publishing-digital-age/.
} 
says ${ }^{4}$ the digital stage is not a matter of merely technical issues, but a vital process that shapes the entire research methodology. This project represents a typical application of digital humanities to an editorial product.

However, apart from some pioneering experimentation, the digital monograph genre is not widespread and it faces resistances from editors, authors, publishers, etc. The reasons for these objections are many and considerable; they concern questions of evaluation, obsolescence, experimentation costs, trade and, more broadly, a general tendency to tradition.

\section{Publishers: tension between cultural logic and business efficiency}

Especially in the countries without a strong tissue of University Presses, for example in Italy, the commercial publishers' involved in academic monograph publishing need to balance scholarly quality with business efficiency, being sustainable and in accordance with their mission. It goes without saying that the digital turn has deeply affected the entire knowledge value chain: production, evaluation, distribution, marketing, use, etc.

For centuries, printed products such as books and journals were the only content media a publisher had to control and take care of, with clear supply chain responsibilities and roles. In parallel with the wider technological developments over the past 15 years (such as growth of the Internet), the academic and professional publishing industry has seen a rapid evolution of new digital publication channels and content formats that have become valuable parts of a publishing house's product portfolio. (Campbell 2012, 195)

For the last twenty years, reflecting the general trend in trade, e-commerce has also been playing a key role in the publishing market. Nevertheless, from a cultural and scholarly perspective, it's important to focus not only on how to sell, but also on what you sell. Generally speaking, e-commerce is any type of commercial transaction that is handled on the Internet, without differentiation about the materiality of the "object" that is sold. In cultural industry in general, the transition from marketing of physical objects to marketing of digital object is almost complete, except for some areas, indeed, such as monographs. Some would argue that e-book format monographs are "digital objects", and this is true, from a technical point of view. But if we think about the disruptive potential of the $\mathrm{DH}$ tools and research methods, e-book will only feel like a transposition of the same content from one medium to another (with really few enhancements like annotations, highlighting and the like), as we said before.

\footnotetext{
${ }^{4}$ http://stanfordpress.typepad.com/blog/2015/01/the-digital-pilot.html
} 
In any case, it must be said that many publishers, in recent years, have developed different and valuable kinds of online products such as databases, encyclopaedias, collections, archives, teaching apps and tutoring sessions. To name a few, recently Bloomsbury has been developing a Digital Resources section of HSS (Humanities and Social Sciences) scholarly contents that seems to be very promising; the Italian II Mulino, for its part, has built the e-learning platform Pandoracampus, which host enhanced academic textbooks. Also journals have found their digital way, which is functioning well and provides many advantages in terms of accessibility and dissemination (Campbell 2011), which has rapidly become a scholarly shared practice. Nevertheless, the field of the academic monograph is different because, unlike the journal articles, it is characterized by the long-form critical issue. The mere digitizing of the textual form is an inadequate attempt that ignores the require of the genre's enhancement.

What is certain is that monographic scholarly works strongly need to find their own "digital way" to survive avoiding the danger of marginalization, and this is possible only with a shared effort led by academic publishers. In fact, despite the considerable problems of evaluation (there still does not exist a common standard for the assessment of this kind of scholarly products) and opposition to the digital methodological shift, scholars need to have the right editorial conditions for publishing high-quality products, that would benefit publishers both from reputational and commercial points of view.

If the monograph's precarious situation derives from an assembly of economic and formal problems, it goes without saying that a possible solution must consider both these aspects carefully. Nowadays the publishers' imperative is to ask about what research needs and how publishers themselves could meet demand in a sustainable way.

The new way scholars carry out humanistic research is strictly linked with digital humanities paradigm. Lagging behind STM (scientific, technical and medical) early development (Casalini 2016), nowadays more and more scholars uses digital tools and resources to conduct their studies: from the simple access and consultation of primary and secondary sources, to the emergence of new methodological perspective like distant reading made via textual analysis technology, to technical innovations like GIS mapping and VR reconstruction. So, if the DH tools and methods developed by scholars and institutions are so useful and significant, why shouldn't they play a key role also in the communication of the research they produce? If we have a chance to better represent the philosophical and technological complexity of our work, why shouldn't we implement it? Moreover, in the field we are talking about, the peculiarity is that often the authors and the users coincide (Thompson 2016, 84) or are very close culturally speaking, making this operation necessary and, in a sense, easy. 


\section{A container for digital monographs}

Once publishers understand the core problem of reshaping monographs, it could be useful for them to lead the transition, in order to regain and keep the central role they play in the scholarly world. To do this, they have to provide the right publishing environment, in order to allow scholars to carry over into the publication stage the enhanced tools and methodologies they have used during research. Broadly speaking, this entails the creation of a system that allows authors and readers to complete the digital switch. Creating a structured publishing system is no minor matter: there have been several isolated attempts so far, especially in academia, but the editorial role of publishers so far has been too weak in this area.

Similar to ways in which this occurs in print monographs, this system should be based on a specific editorial workflow underlying the digital environment which hosts and delivers the digital monographs. The editorial products under consideration are complex digital objects that need a platform not only to be created but also to be used and then purchased, and the process does not end here. The idea of a "place" for these products is also a cultural and philosophical matter, because it provides the legitimacy, substance and robustness that every experiment needs in order to become practice. In the double approach we are adopting, the role of the publisher is fundamental and resembles what it used to be: a mix of technical effort and cultural influence. The platform, therefore, is not only a container of single editorial products, but becomes the medium for scholarly and cultural experience constantly updated, meeting the horizontal requests of digital fruition. The user has at his/her disposal a space for getting around, choosing and operating according to his/her interests.

Broadly speaking, there are two dimensions on which publishing stakeholders must focus: a micro and macro one. The first refers to the quality of the single monographic work and requires scholarly as well as technical work. It implies a strong dialogue between publishers and authors, an awareness of humanistic research methods and tools on the part of the publishers as well as awareness of the continuous innovations provided by $\mathrm{DH}$ on the part of the authors. The macro dimension is, on the other hand, quantitative, based on the need of building an efficient infrastructure for contents aggregation, dissemination and purchasing.

These two focuses are as two sides of the same coin and deserve to be handled in conjunction with each other through a workflow that allows performance of all the steps involved within the digital publishing platform itself.

In recent years, platformization is one of the most visible digital phenomena (to the point where a new field of media studies has been born and dubbed "platform 
studies"5). This term refers to the word "platform" in all its different meanings, emphasising its magnitude:

This more conceptual use of "platform" leans on all of the term's connotations: computational, something to build upon and innovate from; political, a place from which to speak and be heard; figurative, in that the opportunity is an abstract promise as much as a practical one; and architectural [...]. (Gillespie, 352)

One of the most likely scenarios is the creation of a monographic series that, unlike print counterpart, is characterised not by topics or layout, but by similarity in format. We will discuss about micro and macro dimensions respectively as the backend workflow and the front-end of the platform; starting from the micro.

The first phase of the workflow is that of writing or, perhaps more accurately, creation: this is author's responsibility but could also include the assist of a specialist that supports the work of composing the research output, favoring a reasoned and functional use of the potential offered by digital writing environment. This could be, in a mash-up perspective, the open Scalar platform (created by the Alliance for Networking Visual Culture), which is absolutely one of the best tools available; it is not by chance that Scalar is used for the most significant and pioneering ongoing experiments of digital monographs. ${ }^{6}$ This tool offers an excellent balance between standardization and flexibility, includes both a standard user interface and the possibility of customization, lends itself optimally to research needs, and has good portability.

The second phase is the copyediting of text, which is expected to be consistent with the principles of digital rhetoric and which must be made, by the editor, technologically suitable for publication on the platform. After the joint work of the author(s) and editors, and after the "digital proofs" have been carried out in the backend, the monograph is ready to be evaluated by one or more external reviewers, in order to guarantee consistency and scientific legitimacy. This process can also be carried out on the back-end, where the contents, which the reviewer can access by invitation are uploaded. Once ready and approved, the work is published by the publisher in the chosen section of the platform.

Turning to the macro-dimension, with the goal of a strong editorial imprint in mind, the infrastructure that hosts the series should be linked to or could even be a section of the publisher's website. Thinking of an ideal user interface, it could be divided into three sections: one to explain the project, one to stimulate the interest and

\footnotetext{
${ }^{5} \mathrm{http}: / /$ platformstudies.com/.

${ }^{6}$ As an example see Pathfinders: «co-authored by Dene Grigar and Stuart Moulthrop and funded by a grant from the National Endowment for the Humanities, is a multimedia, open source book that documents the experience of early digital literature, specifically pre-web hypertext fiction and poetry, from 1986-1995».
} 
the last to use the contents. The first is conceived as a presentation of editorial choices, of theorical and technical issues linked to the series; the second is a kind of enhancedblog that promotes users' engagement and interaction through documentations of ongoing publications, considerations and debates on content and methodological issues, comments and sharing between authors and publisher and among authors themselves. The last section would be the real container of publications. The whole thing is structured with an eye to the coordination of its parts, guiding the user through different levels of fruition and access.

\section{A business model for the monograph series}

According to Magretta, business models are the result of two parts: the first consists of activities related to making something (designing, manufacturing, etc.), the second concerns the activities connected to selling something (finding customers, distributing the product, etc.). So, as the author says, a new business model's plot could design a product for a specific purpose, or could represent an innovation in selling or delivering an existent service or goods. The first part, which we called the microdimension, is the one that designs new editorial products for an unmet need; the second, the macro-dimension, is our better way of selling or distributing these products.

To be appealing, digital monographs have to be innovative and offer something that print monographs cannot: this is strictly linked with the $\mathrm{DH}$ paradigm, as we said before, and is something very similar to what Ball and Douglas call design-as-argument. This is the foundation of web-text (also called screen-based text, liquid text, etc.) and defines the reshaping which is both formal and substantive: design and technology of text are not disconnected from contents but allow enhancement both in representing and in making scholarly meaning.

These are the words of Massimo Riva about his pilot digital monograph that Brown University selected to take part in the Mellon Foundation project about scholarly communication in the humanities mentioned above:

[...] what really excited me was the very nature of my topic: in which the visual component - being focused on the genealogy of modern visual culture - was so central, and not only, as we shall see, from the point of view of the subject matter but also from that of the very argument I wanted to "build." Leveraging the vast reservoir of images or videos documenting my objects of research available on the web, or in library and museum archives, or even private collections, and doing it in an innovative way, made possible by the dynamic flexibility and multimedia capability provided by a digital platform, would have made the "illustration" of my argument much richer, easier, and more effective. (Riva 2017) 
Benefits in building the argument digitally are clear for the author and will be massive for the "reader" that will face the work with a much more performative knowledge infrastructure than the one he/she is used to. It is not inconceivable that, thanks to the possibility of various interpretative levels, such kinds of products could expand and differentiate the catchment area: if the insider benefits from experiencing sources, methods, tools, etc. used by the scholar, then an outside or non-expert reader can be facilitated in following the argument by multimedia, non-linear, and interactive features. This process is called audience development and it's crucial for the expansion and sustainability of cultural industries; it's geared towards three main objectives: extension of the target, differentiation of the target, improvement of the relation between producer and target (Bollo).

In this regard, we can turn to the second part of Magretta's statement about the activities associated with selling something. This part concerns our digital platform, representing a socio-cultural occurrence set in a computational "space" of participation and exchange. In some sectors like publishing, due to their cultural nature, the web platform also carries further implications like a strong sense of community and similarity, a tendency to loyalty and the willingness of cultural engagement. The publisher's responsibility to guarantee quality encourages both authors and users to trust the platform, which becomes a sort of cultural brand. And this is, obviously, the key card of the whole system.

Considering that the product economy is inexorably shifting towards the economy of services in which licenses are displacing traditional acquisitions, the most advantageous option seems to be a subscription solution, already widely tested and consolidated in contiguous digital areas such as TV, music, and magazines. Especially in fields like publishing, the subscription model has some unquestionable advantages: it gives the user a stake in the content creation process, it lowers the costs for each subscriber spreading them over a large audience, and it incentivizes long-term value creation (Anderson). The intent, in fact, is not to sell a single monograph to the reader, but to retain him/her and to gain its interest, even economically, through the continuous, variegated and prestigious offer of scientific and cultural products. The latter, which in the publishing platform project in question are the articles and contents of the "blog section", are open, as they constitute the viaticum for the subscriber's access to the monographs; of which, from the outside, only titles and short previews are visible. Thus, the transformation of the single-monograph reader/user in a scholarly platform subscriber/member is completed. 
To conclude, the kind of workflow we described, whose decisive feature is the carrying out of all the operations (from writing to purchasing) on a single, self-contained digital infrastructure, allows publishers to completely eliminate the cost of printing, intermediation and distribution. They have to take care, instead, of the one-off costs of the platform's design and implementation, updating and (possibly) creative consultancy during the writing stage.

\section{Conclusions}

Digital culture and technology have modified habits, behavior, practices, approaches and understandings in many domains of human life; scholarly communication is no exception. Starting from this paradigm shift we focused on scholarly monographs in the humanities, which for years have been affected by a chronic illness because of external as well as internal generic factors. Thanks to some ongoing projects, especially in the Anglophone context, a new way of conceiving monograph digitally is emerging. This has nothing to do with the e-book format, but is based on $\mathrm{DH}$, which operate in the interaction between the digital-textuality layer (making it multimodal, fluid, media-rich, interactive, non-linear) and the new technical and methodological way of conducting research thanks to digital tools. Commercial publishers act within this framework, always trying to balance their goal of scholarly quality with the business dimension, and technical effort with cultural influence in the digital environment. A strategy to finally establish and valorise digital monographs must proceed in two complementary dimensions (both orientated towards audience development): the first, which we called the micro, is the dimension of design and products creation while ensuring quality standards; the second, which we called the macro, is the dimension of product sale. To this end we have envisioned the development of a publishing platform that supports a specific workflow and creates a cultural community that identifies itself with the values of the knowledge infrastructure. We conclude that the most suitable business model to make such a project sustainable is the subscription solution, which indeed is the most common scheme in the current cultural industry. When goods become services and acquisitions become licenses, users will become subscribers in their turn, initiating a lasting and trusting relationship with producers. 


\section{Bibliography}

Anderson, Kent. "Hiding in Plain Sight - Is the Subscription Model the Optimal Business Model for the Digital Age?", The Scholarly Kitchen, 2014, https://scholarlykitchen.sspnet.org/2014/06/30/hiding-in-plain-sight-is-thesubscription-model-the-optimal-business-model-for-the-digital-age/.

Bollo, Alessandro. "50 Sfumature di Pubblico", I Pubblici della Cultura. Audience Development, Audience Engagement, De Biase, Francesco (edited by), Milano, Franco Angeli, 2014.

Campbell, Robert, and Meadows, Alice. "Scholarly Journal Publishing: Where Do We Go from Here?", Learned Publishing, 24, 2011, pp. 171-81, https://doi.org/10.1087/20110305.

Campbell, Robert, Pentz, Ed, and Borthwick, lan (edited by). Academic and Professional Publishing, Oxford, Chandos Publishing, 2012.

Casalini, Michele. Humanities and Social Sciences Academic Content in the Era of Digital Transition, VALA Conference, february 2016.

Darnton, Robert. "The New Age of the Book", New York Review of Book, vol.46, no. 5, 1999.

Douglas, Eyman, and Ball, Cheryl E. "Digital Humanities Scholarship and Electronic Publication", Rhetoric and the Digital Humanities, Ridolfo, Jim, and Hart-Davidson, William (edited by), Chicago, University of Chicago Press, 2015, pp. 65-79.

Finkelstein, David, and McCleery, Alistair (edited by). The Book History Reader, Oxon, Routledge, 2006.

Fitzpatrick, Kathleen. Planned Obsolescence: Publishing, Technology, and the Future of the Academy, New York, NYU Press, 2011.

Gere, Charlie. Digital Culture, London, Reaktion Books, 2009.

Greco, Albert N., Rodríguez, Clara E, and Wharton, Robert M. Culture and Commerce of Publishing in the Twenty-First Century, Palo Alto, Stanford University Press, 2006.

Gillespie, Tarleton. "The Politics of Platforms", New Media and Society, vol. 12, no. 3, 2010, pp. 347-64.

Gordon, Linda C., Kung, David S., and Dyck, Harold. "Strategic Use of E-commerce in the Transformation of the Publishing Industry", Communications of the IIMA, vol. 8, no. 4, 2008, pp. 65-78.

Hall, Frania. The Business of Digital Publishing. An Introduction to the Digital Book and Journal Industries, Oxon, Routledge, 2013. 
Hands, Joss. "Introduction: Politics, Power and 'Platformativity'”, Culture Machine, vol. 14, 2013, pp. 1-9.

Helmond, Anne. "The Platformization of the Web: Making Web Data Platform Ready", Social Media + Society, 2015, https://doi.org/10.1177/2056305115603080.

Janneke, Adema. “The Monograph Crisis Revisited”, Open Reflections, 2015, https://openreflections.wordpress.com/2015/01/29/the-monograph-crisisrevisited/.

Lyubareva, Inna, Benghozi, Pierre-Jean, and Fidele, Teaiki. "Online Business Models in Creative Industries", International Studies of Management \& Organization, vol. 44, no. 4, 2014, pp. 43-62, http://dx.doi.org/10.2753/IMO0020-8825440403.

Magretta, Joan. "Why Business Models Matter", Harvard Business Review, 2002, https://hbr.org/2002/05/why-business-models-matter.

Riva, Massimo. "An Emerging Scholarly Form: the Digital Monograph”, Digitcult, vol. 2, no. 3, pp. 63-74, 2017,

http://dx.doi.org/10.4399/97888255099087.

Riva, Massimo. "Liquid/Cloudy/Foggy: For a Critique of Fluid Textuality", in Humanist Studies \& the Digital Age, vol. 2, no. 1, 2012, http://dx.doi.org/10.5399/uo/hsda.2.1.3016.

Santoro, Marco. "Pubblicazioni Cartacee e Pubblicazioni Digitali: Quale Futuro per la Comunicazione Scientifica", Memoria e Ricerca, vol. 8, 2001, http://www.sissco.it/articoli/linguaggi-e-siti-la-storia-on-line-784/pubblicazionicartacee-e-pubblicazioni-digitali-quale-futuro-per-la-comunicazione-scientifica789/.

Schwartz, Andersson J. "Platform Logic: an Interdisciplinary Approach to the Platformbased Economy”, Policy and Internet, vol. 9, no. 4, 2017, pp. 374-394.

Scupola, Ada. "The Impact of Electronic Commerce on the Publishing Industry: towards a Business Value Complementarity Framework of Electronic Publishing", Journal of Information Science, vol. 25, no. 2, 1999, pp. 133-145.

Thatcher, Stanford G. "Thinking Systematically about the Crisis in Scholarly Communication", The Specialized Scholarly Monograph in Crisis: Or How Can I Get Tenure If You Won't Publish My Book?, Case, Mary (edited by), Washington DC, Association of Research Libraries, 1999.

Thompson, John. Books in the Digital Age: The Transformation of Academic and Higher Education Publishing in Britain and the United States, Cambridge, Polity, 2005. 
Watkinson, Anthony. Electronic Solutions to the problems of Monograph Publishing, The Council for Museums, Archives and Libraries Research Reports, 2001, http://ciber-research.eu/download/WatkinsonElectronic_Solutions_to_the_Problems_of_Mongraph_Publishing.pdf.

Webster, James. The Marketplace of Attention: How Audiences Take Shape in a Digital Age, Cambridge, MIT Press, 2014.

Weller, Martin. The Digital Scholar, London, Bloomsbury, 2011.

Williams, Peter, Stevenson, lan, Nicholas, David, Watkinson, Anthony, and Rowlands, Ian. "The Role and the Future of the Monograph in Arts and Humanities", Aslib Proceedings, vol. 61, no. 1, 2009, pp. 67-82 https://doi.org/10.1108/00012530910932294.

Willinsky, John. "Toward the Design of an Open Monograph Press", Journal of Electronic Publishing, vol. 12, no. 1, 2009.

URLs accessed 08/15/2018. 